\title{
Hyperuricemia; a warning sign of future cardiovascular events and chronic kidney disease
}

\author{
Farahnak Assadi* \\ Department of Pediatrics, Section of Nephrology, Rush University Medical Center, Chicago, IL, USA
}

\section{A R T I C L E I N F O}

Article Type:

Editorial

\section{Article History:}

Received: 8 September 2017

Accepted: 1 November 2017

ePublished: 12 November 2017

\section{Keywords:}

Uric acid

Hypertension

Microalbuminuria

Chronic kidney disease

Cardiovascular disease
Implication for health policy/practice/research/medical education:

Strategies to lower the incident of hypertension associated-cardiovascular disease should include monitoring serum uric acid level, and if its level is higher than $5.5 \mathrm{mg} / \mathrm{dL}$, treatment with allopurinol should be initiated.

Please cite this paper as: Assadi F. Hyperuricemia; a warning sign of future cardiovascular events and chronic kidney disease. J Nephropharmacol. 2018;7(1):1-2. DOI: 10.15171/ npj.2018.01.

\section{Introduction}

Obesity-related hypertension (HTN) in children and adolescents is frequently associated with elevated serum uric acid (UA) levels, high sensitivity C-reactive protein (CRP), and microalbuminuria (MA) (1-3). More than $70 \%$ of children with essential HTN have elevated serum UA levels above $5.5 \mathrm{mg} / \mathrm{dL}$ (4). Obese children with elevated uric acid (UA) have a higher prevalence of cardiovascular disease (CVD) risk factors (5). Elevated UA is also independent risk factors for faster progression of chronic kidney disease (CKD) in both children and adolescents (6).

The UA-induced HTN is mediated through the activation of the renin-angiotensin system (RAS), down regulation of nitric oxide, and vascular endothelial dysfunction (7-9). In a recent study, Feig et al reported on 30 adolescent aged 11-19 years with newly diagnosed essential HTN and serum UA level of $>6 \mathrm{mg} / \mathrm{dL}$. The participants were treated with allopurinol and placebo for 4 weeks with 2 weeks washout periods between treatments (10). Twenty of 30 patients achieved normal blood pressure (BP) while taking allopurinol compared to one patient while taking placebo $(P<0.01)$.

More recently, Assadi sought to investigate whether UA-lowering agent in combination with angiotensin converting enzyme inhibitor (ACEI) can reduce BP more effectively in children with essential HTN than the ACEI (11). In this randomized clinical trial 44 adolescents, aged 12-19 years, received either enalapril alone or enalapril plus allopurinol for 8 weeks. Baseline serum UA level ( $\geq 5.5 \mathrm{mg} / \mathrm{dL})$, mean $\mathrm{BP}$, age, and body mass index (BMI) were similar between the 2 groups. After 8 weeks, treatment, mean BP and serum UA level were lower in the combination treatment group compared with enalapril group. The results suggest that lowering serum UA level with allopurinol should be considered in hypertensive children with elevated UA greater than $5.5 \mathrm{mg} / \mathrm{dL}$ (8). In another study, Assadi examined the therapeutic effect of microalbuminuria (MA) lowering on regression of left ventricular hypertrophy (LVH) in 54 hypertensive children and adolescents between 11-19 years old (12). All participants were receiving concomitant treatment with hydrochlorothiazide and ACEI. Baseline and 12-month follow-up assessment of left ventricular mass index (LVMI) and urine MA/creatinine ratio (MA/Cr), were obtained. MA was expressed as MA/Cr $>30 \mathrm{ug} / \mathrm{mg}$. Weight, body surface area BMI, mean arterial pressure, and MA were all univariate correlates of LVMI. In a multiple regression analysis, a significant relationship was found between LVMI and MA, BMI and mean arterial pressure. MA had the most significant correlation with LVMI at follow-up, suggesting that MA-lowering agents may halt or slow the progression of LVH in children and adolescent with essential HTN (10).

In a more recent clinical trial, Lauren and colleagues reported on 49 hypertensive children, aged 3-19 years 
with hyperuricemia who had completed both baseline and 12-month evaluations. At baseline, 24\% had serum UA greater than $5.5 \mathrm{mg} / \mathrm{dL}, 52 \%$ were either overweight or obese, and $39 \%$ had LVH (13).

High-sensitivity CRP, low high-density lipoprotein, and LVMI were all significantly associated with elevated serum UA levels at baseline. Each $1 \mathrm{mg} / \mathrm{dL}$ increase in baseline UA was associated with a $2.5 \mathrm{~g} / \mathrm{m} 2.7$ increase in the LVMI overtime. However, this association was no longer significant after adjustments for changes in serum UA, BP and medication use at 1-year follow-up. These findings suggest that hypertensive children with elevated serum UA have a higher prevalence of obesity-related CVD risk factors and that UA may be a marker of obesity and not an independent CVD risk factor (7).

Rodenbach et al assessed the impact of hyperuricemia on progression of CKD on over 600 children and adolescent with a median age of 12.3 years (6). They reported, older age, male gender, lower GFR and BMI >95th percentile were associated with higher serum UA levels and faster progression to $\mathrm{CKD}$. High $\mathrm{BP}, \mathrm{CKD}$, and raised urine protein-creatinine ratio were also associated with faster times to the CKD progression. Authors concluded that hyperuricemia is an independent risk factor for faster progression of CKD in children and adolescents.

\section{Conclusion}

These studies demonstrate a new potential therapeutic approach, which, require confirmation in larger clinical trials. In the meanwhile, strategies to lower the incident of HTN associated-CVD should include monitoring serum UA level, and if its level is higher than $5.5 \mathrm{mg} / \mathrm{dL}$, treatment with allopurinol should be initiated. Further, it is highly likely that UA-lowering therapy in children with CKD could also slow the disease progression.

To date, no published studies have evaluated the therapeutic effects of allopurinol to retard disease progression among children and adolescents with CKD. Thus, controlled, randomized, and longitudinal clinical trials are warranted to examine this hypothesis.

Author's contribution

FA is the single author of the manuscript.

\section{Conflicts of interest}

The author declared no competing interests.

\section{Ethical considerations}

Ethical issues (including plagiarism, data fabrication, double publication) have been completely observed by the author.

\section{Funding/Support}

None.

\section{References}

1. Soletsky B, Feig DI. Uric acid reduction rectifies prehypertension in obese adolescents. Hypertension. 2012;60:1148-56.

2. Hoffmann IS, Jimenez E, Cubeddu LX. Urinary albumin excretion in lean, overweight and obese glucose tolerant individuals: its relationship with dyslipidaemia, hyperinsulinaemia and blood pressure. J Hum Hypertens. 2001;15:407-12

3. Assadi F. Relation of left ventricular hypertrophy to microalbuminuria and C-reactive protein in children and adolescents with essential hypertension. Pediatric Cardiol. 2008;29:580-4.

4. Rebestine J, du Cailar G,Mimran A. Combined renal effects of overweight and hypertension. Hypertension. 1995;26:610-5.

5. Assadi F. The growing epidemic of hypertension among children and adolescents: a challenging road ahead. Pediatr Cardiol. 2012;33:1013-20. doi: 10.1007/s00246-012-0333-5.

6. Rodenbach KE, Schneider MF, Furth SL, Moxey-Mims MM, Mitsnefes MM, Weaver DJ, et al. Hyperuricemia and progression of $\mathrm{CKD}$ in children and adolescents: the Chronic Kidney Disease in Children (CKiD) Cohort Study. Am J Kidney Dis. 2015;66:984-92. doi: 10.1053/j. ajkd.2015.06.015.

7. McMullan CJ, Borgi L, Fisher N, Curhan G, Forman J. Effect of uric acid lowering on renin-angiotensin-system activation and ambulatory BP: a randomized controlled trial. Clin J Am Soc Nephrol. 2017;12:807-816. doi: 10.2215/ CJN.10771016.

8. Saddekni MB, Saag KG, Dudenbostel T, Oparil S, Sattui SE, et al. The effects of urate lowering therapy on inflammation, endothelial function, and blood pressure (SURPHER) study design and rationale. Contemp Clin Trials. 2016;50:238-44. doi: 10.1016/j.cct.2016.08.016.

9. George J, Carr E, Davies J, Belch JJ, Struthers A. High-dose allopurinol improves endothelial function by profoundly reducing vascular oxidative stress and not by lowering uric acid. Circulation. 2006;4:2508-16.

10. Feig DI, Soletsky B, Johnson RJ. Effect of allopurinol on blood pressure of adolescents with newly diagnosed essential hypertension: a randomized trial. JAMA 2008;300:924-32. doi 10.1001/jama.300.8.924.

11. Assadi F. Allopurinol enhances the blood pressure lowering effect of enalepril in children with hyperuricemic essential hypertension. Nephrology. 2014;27:51-6. doi: 10.1007/ s40620-013-0009-0

12. Assadi F. Effect of lowering microalbuminuria on regression of left ventricular hypertrophy in children and adolescents with essential hypertension. Pediatr Cardiol. 2007;28:27-33.

13. Reschke LD, Miller ER, Fadrowski JJ, Loeffler LF, Holmes KW, Appel LJ, et al. Elevated uric acid and obesity-related cardiovascular disease risk factors among hypertensive youth. Pediatr Nephrol. 2015;30:2169-76. doi: 10.1007/ s00467-015-3154-y.

Copyright $\odot 2018$ The Author(s); Published by Society of Diabetic Nephropathy Prevention. This is an open-access article distributed under the terms of the Creative Commons Attribution License (http://creativecommons.org/licenses/by/4.0), which permits unrestricted use, distribution, and reproduction in any medium, provided the original work is properly cited. 